\title{
WHAT CAN BE DONE WITH THE ACETYL GROUP OF ARYL-1- ETHANONES?
}

\author{
Fliur Macaev \\ Institute of Chemistry of the Academy of Sciences of Moldova, Academiei str. 3, MD-2028 Chişinău, Republic of Moldova \\ E-mail: flmacaev@cc.acad.md, Phone (+373-22) 73-97-54,Fax (+373-22) 73-99-54
}

\section{Dedicated to academician Vlad Pavel on his $70^{\text {th }}$ birthday}

\begin{abstract}
Literature data on utilization of acetyl group of aryl-1-ethanones (acetophenones) for the synthesis of organic compounds is generalized. Different approaches of preparation of aromatic compounds by chemical transformations of methyl as well as keto- group of titled compounds are systematized. Examples of the synthesis of organic compounds based on products of primary transformations of aryl-1-ethanones are considered.
\end{abstract}

Keyword: organic synthesis, aryl-1-ethanones, acetyl group

\section{Content}

1. Introduction

2. Syntheses with retention of methyl group

3. Syntheses where keto group is retained

4. Syntheses where both groups of acetyl fragment are transformed

5. Synthetic schemes based on the products of primary transformation of acetyl group

6. Conclusions

7. Acknowledgments

8. References

\section{Introduction}

Aryl-1-ethanones (acetophenones) $\mathbf{1}$ are convenient starting substances for the synthesis of various classes of organic compounds. Their acetyl group can be subjected to various transformations leading to formation of a number of substances, including heterocyclic compounds with various dimensions of cycles, number and nature of heteroatoms. Moreover, different substituents in the aromatic ring of $\mathbf{1}$ can significantly increase the diversification of synthesized products.

Acetophenones are useful models for the development of different synthetic methods. The syntheses of heterocyclic compounds, based on products of primary transformation of aryl-1-ethanones, are considered in a number of monographs $[1,2]$ and reviews $[3,4]$.

Current review is concentrated mostly on data, published in last 15 years, and investigations, which are not included in the earlier articles [1-4].

Based on the structure of aryl-1-ethanones, usually, reagents interact with methyl or carbonyl group. Further transformation of obtained substances leads to products with a larger or smaller amount of carbon atoms than starting compounds, and this overview will be presented as four main parts: a) syntheses with retention of methyl group; b) syntheses where keto group is retained; c) syntheses where both groups of acetyl fragment are transformed; d) synthetic schemes based on the products of primary transformation of acetyl group.

\section{Syntheses with retention of methyl group}

Among the large number of products of transformations of $\mathbf{1}$ with retention of methyl group, the first to be mentioned are 1,3-dioxolanes 3, which are stable under neutral and basic condition. The most convenient and practical method for their synthesis is the reaction of ketones $\mathbf{1}$ with 1,2-diols $\mathbf{2}$ in presence of an appropriate catalyst.

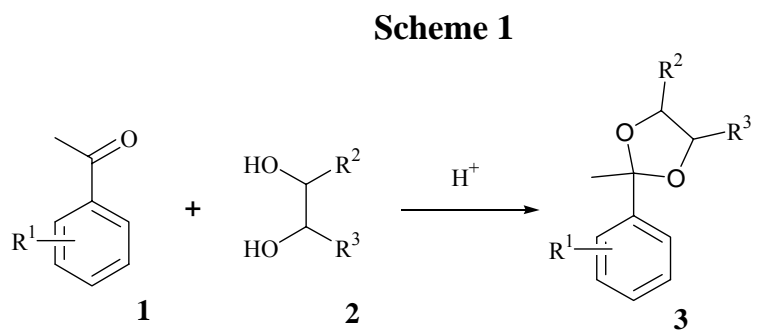

It should be mentioned that the reaction is reversible and proceeds at the presence of acid catalysts [5]. Good yields of 1,3-dioxolanes have been obtained in the presence of an oxalic acid, benzene or toluene sulfonic acids, $\mathrm{HClO}_{4}, \mathrm{ZnCl}_{2}$, $\mathrm{BF}_{3}$-etherate, $\mathrm{SnCl}_{4}$ etc. For example, the synthesis of 3 in the presence of the $\mathrm{Ti}^{4+}$-exchanged montmorillonite as a strong solid acid catalyst is described [6]. Other different heterogeneous catalytic systems are used also: natural kaolinic clay, zeolite HSZ-360, sulfated polystyrene clays, polymers corporate with different metals, triphenylphosphine iodide 
[7-10]. Such catalysts have been separated by simple filtration and the possibility for the recycling process was indicated.

The cyclization of substituted benzene derivatives is an important strategy for the synthesis of benzanellated heterocyclic compounds [11]. The synthetic introduction of electrophilic substituents into position $2\left(\mathrm{R}^{2}=\mathrm{H}\right)$ or 6 $\left(\mathrm{R}^{2}=\mathrm{Me}\right)$ of $\mathbf{4}$ have led to compounds $\mathbf{7}$, and carried out via preliminary prepared of ketals 5,6.

\section{Scheme 2}

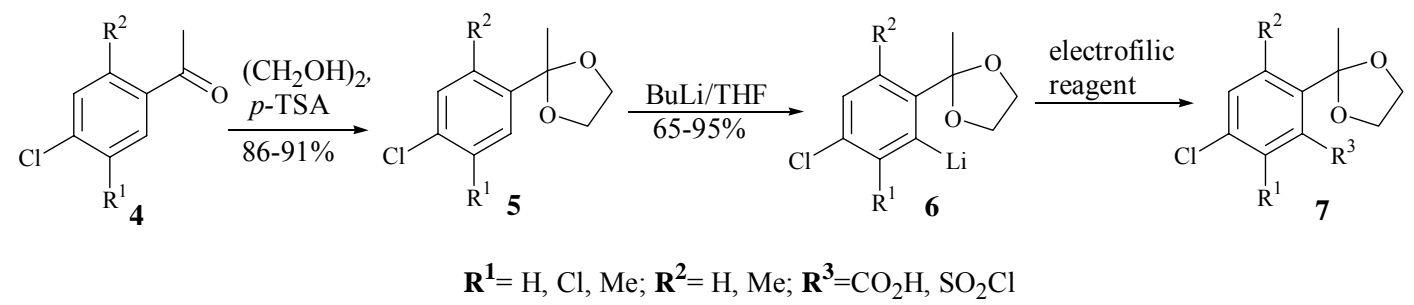

Thiosemicarbazones of aryl-1-ethanones are well known to form stable complexes with transition elements and heavy metal ions. Synthesis and applications of these chelating ligands were also reported [12-14]. The similar strategy was employed for the preparation of thio-derivatives 9 from 1-(2-hydroxyphenyl)-1-ethanone 8 [15].

\section{Scheme 3}

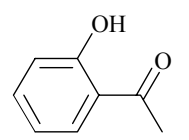

8

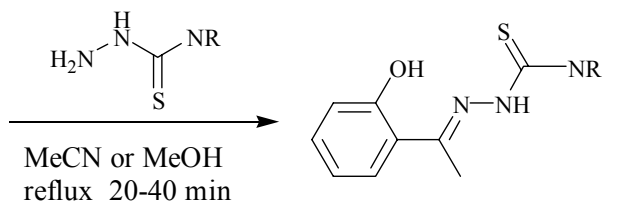

9

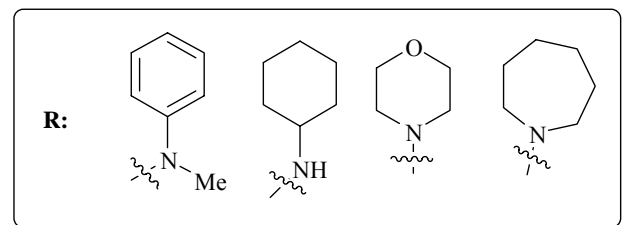

The aryl-1-ethanol chemistry has proved a powerful tool for obtaining C-C, C-N, C-Hal bonds in organic synthesis. Tremendous progresses have been made in the area of asymmetric reduction of discussed ketones to aryl-1-ethanols. Due to extensive body of work carried out in the area of transformation of $\mathbf{1}$, emphasis here is focused on data that were not overviewed in the past and will be presented in the fourth part of the review.

\section{Syntheses where keto group is retained}

The transformations of methyl group of acetophenones provides an obvious entry to further synthesis of practically important heteroatomic compounds $[3,4]$.

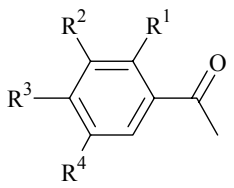

8,10-13

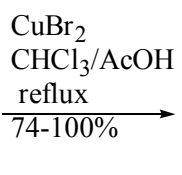

$$
\underset{\text { reflux }}{\stackrel{\mathrm{CHCl}_{3} / \mathrm{AcOH}}{74-100 \%}}
$$

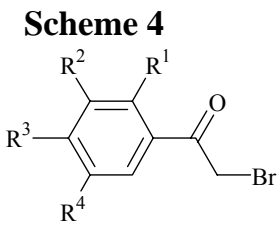

14-18

8,14: $R^{1}=O H, R^{2}=R^{3}=R^{4}=H ; 10,15: R^{2}=O H, R^{1}=R^{3}=R^{4}=H ; 11,16: R^{3}=O H, R^{1}=R^{2}=R^{4}=H$

12,17: $R^{1}=R^{3}=O H, R^{2}=R^{4}=H ; 13,18: R^{1}=R^{4}=O H, R^{2}=R^{3}=H$

\section{Scheme 5}

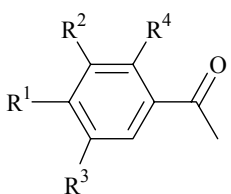

19-26

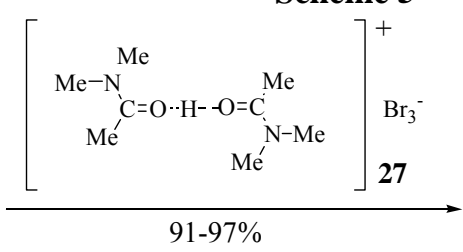

$91-97 \%$

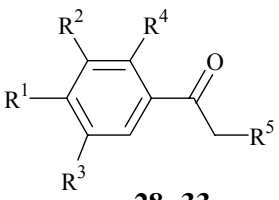

$28-33$

19, 28: $\mathrm{R}^{1}=\mathrm{Cl}, \mathrm{R}^{2}=\mathrm{R}^{3}=\mathrm{R}^{4}=\mathrm{H}$; 20, 29: $\mathrm{R}^{1}=\mathrm{Br}, \mathrm{R}^{2}=\mathrm{R}^{3}=\mathrm{R}^{4}=\mathrm{H}$; 21, 30: $\mathrm{R}^{1}=\mathrm{OMe}, \mathrm{R}^{2}=\mathrm{R}^{3}=\mathrm{R}^{4}=\mathrm{H}$;

22, 31: $\mathrm{R}^{1}=\mathrm{R}^{2}=\mathrm{Cl}, \mathrm{R}^{3}=\mathrm{R}^{4}=\mathrm{H}$; 23, 32: $\mathrm{R}^{1}=\mathrm{R}^{2}=\mathrm{OMe}, \mathrm{R}^{3}=\mathrm{H}, \mathrm{R}^{4}=\mathrm{Me} ; 24 \mathrm{R}^{1}=\mathrm{OMe}, \mathrm{R}^{2}=\mathrm{NO}_{2}, \mathrm{R}^{3}=\mathrm{R}^{4}=\mathrm{H}$; $25 \mathrm{R}^{1}=\mathrm{NH}_{2}, \mathrm{R}^{2}=\mathrm{R}^{3}=\mathrm{R}^{4}=\mathrm{H} ; 26 \mathrm{R}^{1}=\mathrm{NO}_{2}, \mathrm{R}^{2}=\mathrm{R}^{3}=\mathrm{R}^{4}=\mathrm{H} ; 33 \mathrm{R}^{1}=\mathrm{NH}_{2}, \mathrm{R}^{2}=\mathrm{R}^{3}=\mathrm{Br}, \mathrm{R}^{4}=\mathrm{R}^{5}=\mathrm{H}$ 
$\alpha$-Bromoketones art as important intermediates in many synthetic schemes. They can be prepared by direct bromination of acetophenones in various solvents $\left(\mathrm{H}_{2} \mathrm{O}, \mathrm{CHCl}_{3}, \mathrm{CCl}_{4}, \mathrm{AcOH}, \mathrm{EtOH}, \mathrm{MeOH}, \mathrm{DMF}\right)$ or on free solvent conditions [16]. Chemoselective bromination of 1-(hydroxyphenyl)-1-ethanones 8,10-13 into bromides $\mathbf{1 4 - 1 8}$ is achieved by treatment with $\mathrm{CuBr}_{2}$ (scheme 4) [17]. According to another report [18], the system: $\mathrm{Br}_{2}-\mathrm{CO}\left(\mathrm{NH}_{2}\right)_{2}-\mathrm{CH}_{3} \mathrm{COOH}$ has been used as a bromination's reagent, but 27 was more effective [19].

High-yielding protocol for exclusive formation 28-32 from 19-23 using complex 27 was reported. It should be mentioned, that 1-(4-aminophenyl)-1-ethanone 25 has produced 1-(3,5-dibromo-4-aminophenyl)-1-ethanone 33 (yield not indicated) as well as the bromination of $\mathbf{2 4 , 2 6}$ doesn't place. This problem was solved by use of tribromine of 2,4diamino-1,3-thiazole 36 [20].

\section{Scheme 6}

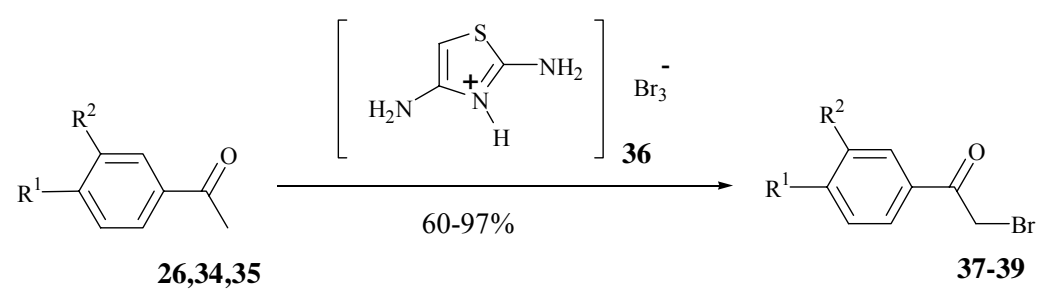

26,38: $\mathrm{R}^{1}=\mathrm{NO}_{2}, \mathrm{R}^{2}=\mathrm{H} ; \mathbf{3 4 , 3 9}: \mathrm{R}^{1}=\mathrm{H}, \mathrm{R}^{2}=\mathrm{NO}_{2} ; \mathbf{3 5 , 3 7}: \mathrm{R}^{1}=\mathrm{R}^{2}=\mathrm{H}$;

The target products 37-39 from 26, 34 and 35 have been prepared according scheme 6.

It is well known that treatment of methylketones with bromine covalent bonding reagents leads to $\alpha$-bromoketo derivatives. For example, hexabromocyclopentadiene has shown good properties as reagent for selective bromination of 35 to 37 (yield 80\%) [21]. A different approach to 37 using the polymer supported bromine Amberlyst-A26 $\mathrm{Br}_{3}{ }^{-}$was described [22], but the yield in this reaction did not exceed $55 \%$.

Chemists still carries out their reactions in solution, even when a special reason for the use of solvent cannot be found. During the last two decades it was found out that many reactions proceed efficiently in solid state. Indeed, in many cases, solid-state organic reaction occurs more efficiently and more selectively than its solution counterpart does, since the molecules in a crystal are arranged tightly and regularly [16]. The investigation of the solvent-free microwaveinduced bromination of 19-21, 26, 34, 35 to 28-30, 37-39 with dioxane-dibromide 40 on the surface of $\mathrm{SiO}_{2}$ was performed. Acidic silica gel has play twofold roles: promoting enol formation from ketone and inducing electrophilic assistance to $\mathrm{Br}-\mathrm{Br}$ bond breaking.

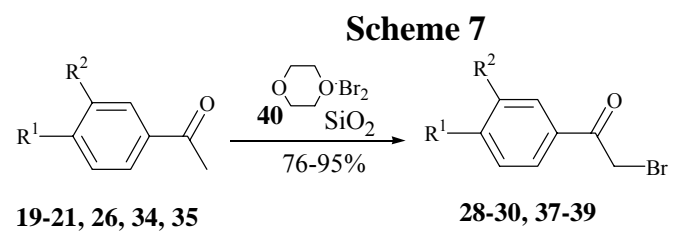

19, 28: $\mathrm{R}^{1}=\mathrm{Cl}, \mathrm{R}^{2}=\mathrm{H} ; 2$ 20, 29: $\mathrm{R}^{1}=\mathrm{Br}, \mathrm{R}^{2}=\mathrm{H}$; 21, 30: $\mathrm{R}^{1}=\mathrm{OMe}, \mathrm{R}^{2}=\mathrm{H}$

26, 38: $\mathrm{R}^{1}=\mathrm{NO}_{2}, \mathrm{R}^{2}=\mathrm{H}$; 34, 39: $\mathrm{R}^{1}=\mathrm{H}, \mathrm{R}^{2}=\mathrm{NO}_{2}$; 35, 37: $\mathrm{R}^{1}=\mathrm{R}^{2}=\mathrm{H}$

Under photochemical conditions, the bromination of compounds 19, 21, 35, 41 with N-bromosuccinimide was performed, and the $\alpha$-bromoketones 28, 30, 37, 42 were obtained [23]. A mixture 37, 43 was synthesized by treatment of acetophenone 35 with NBS in the presence of $p$-toluenesulfonic acid.

\section{Scheme 8}

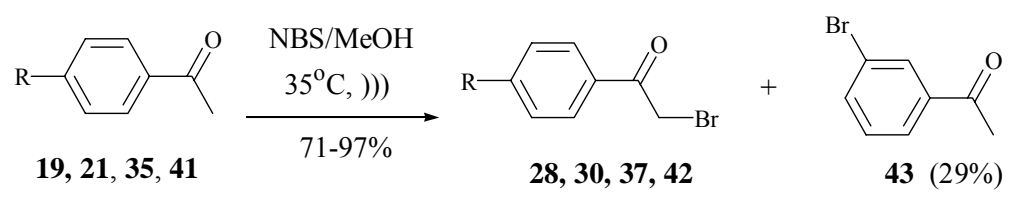

19, 28: $\mathrm{R}=\mathrm{Cl}$; 21, 30: $\mathrm{R}=\mathrm{OMe}$; 35, 37: $\mathrm{R}=\mathrm{H} ;$ 41, 42: $\mathrm{R}=\mathrm{Me}$

Benzylideneacetophenones present a class of naturally and synthetic occurring pigments, which are often referred to as "chalcones" [1, 2, 24-28]. The simplest method of synthesis of chalkones is involving the Claisen-Schmidt reaction. This is a two step reaction of acetophenones 21, 26, 35, 41 with benzaldehyde in the presence of base and result the aldols 44-47 followed by formation $\alpha, \beta$-unsaturated ketones 48-51 (scheme 9). The water formed in this reaction is azeotropically distilled off with xylene. 
Scheme 9<smiles>[R]c1ccc(C(C)=O)cc1</smiles>

21,26,35, 41

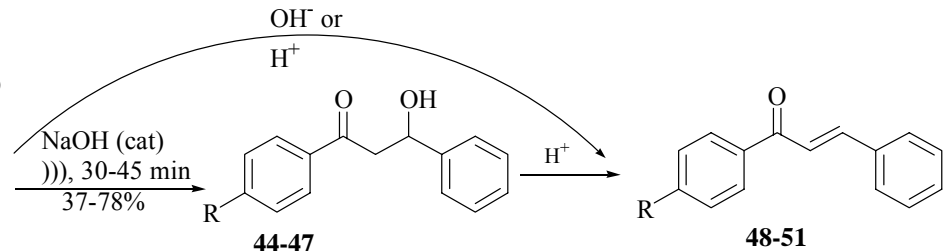

44-47
48-51

The concentration of alkali used for this reaction usually ranges between $10-60 \%$, but in case of fluoro acetophenones it should not be higher than 1,5\% [29]. The use of an acid catalyst has been recommended for prepation of hydroxychalcones [30]. Synthesis of chalcones on the surface of $\mathrm{SiO}_{2}$ was also reported [31]. Selective synthesis of aldols should be performed by use of ultrasound irradiation $[32,33]$.

Another strategy was employed for the preparation of chiral aldol 53 from acetophenone 35 and $1 H$-indole-2,3-dione 52. The condition of Knoevenagel reaction was recommended [34].

\section{Scheme 10}

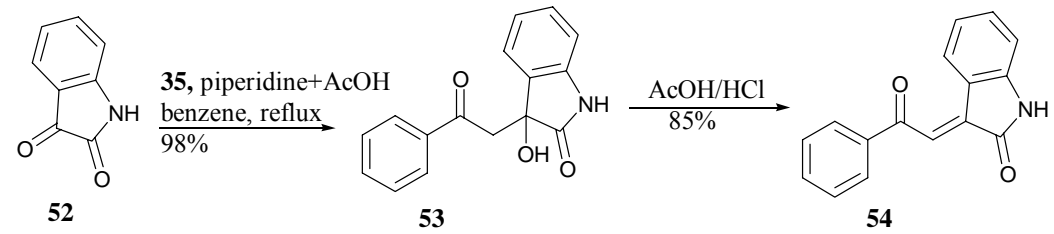

Dehydration of 53 leads to $\mathbf{5 4}$ - homolog of inhibitor of Plasmodium falciparum [35].

\section{Syntheses where both groups of acetyl fragment are transformed}

The $\alpha$-hydroxylation of methyl group of 35, 41 is based on the initial oxidation of enol ethers 55, 56 with 3 chlorobenzenecarboperoxoic acid, chromyl chloride or iodosylbenzene [36-38].

\section{Scheme 11}

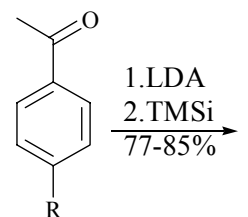

35, 41

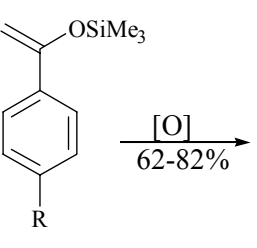

55,56

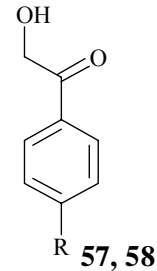

35, 55, 57: $\mathrm{R}=\mathrm{H} ;$ 41, 56, 58: $\mathrm{R}=\mathrm{Me}$

Yields of products 57, 58 are moderate (from 48 up to $70 \%$ ).

Scheme 12<smiles>COC(CO)(OC)c1ccccc1C(C)(C)C1(C(C)C)CO1</smiles>

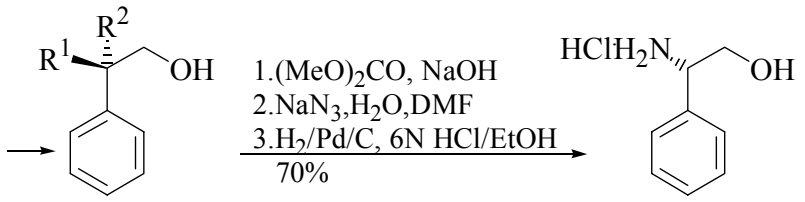

$61 \mathrm{R}^{1}=\mathrm{H}, \mathrm{R}^{2}=\mathrm{OH}$

63

$62 \mathrm{R}^{1}=\mathrm{OH}, \mathrm{R}^{2}=\mathrm{H}$

The direct hydroxylation of acetophenone 35 to 57 is illustrated on the scheme 12 and includes the preliminary formation of enolate anion [39-41]. The elimination of phenyl iodide or - iodo-benzoic acid has accompanied by 
addition of anion MeO- to carbonyl group with formation of epoxide 59, hydroximethylacetal 60, and ketol 57, respectively. The reduction of 57 led to a mixture of epimeric 1,2-diols $\mathbf{6 1 ,} 62$ separated by the use of lipases [42].

The synthesis of the enantiomeric pure amino alcohol 63 from 61 was also reported [43].

Conversion of ketone 35 to the alcohol 64, styrene 65, epoxides 66, 67 and 1,2-diols 68, 69 is presented on the scheme $13[43-47]$.

\section{Scheme 13}

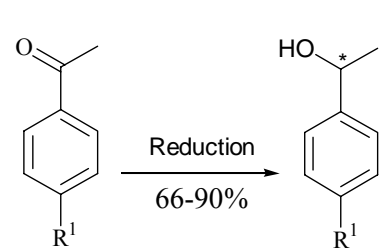

$19,20,35,70$

64, 71-73
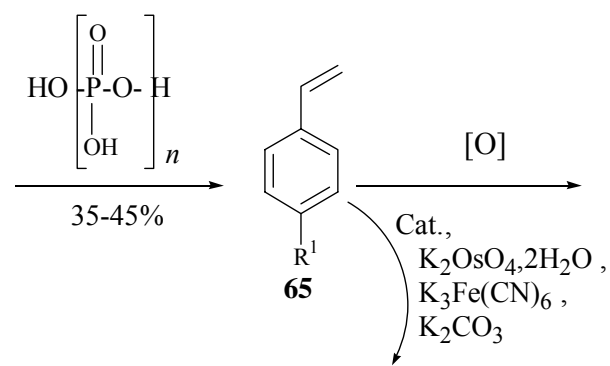

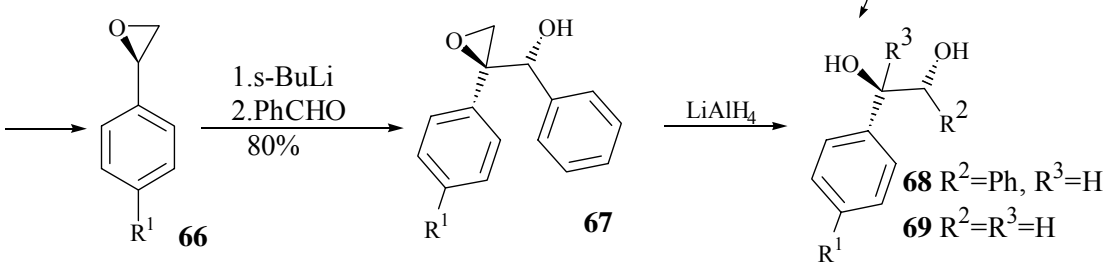

35, 64-69: $\mathrm{R}^{1}=\mathrm{H} ; \mathbf{7 0}, \mathbf{7 1}: \mathrm{R}^{1}=\mathrm{F} ; \mathbf{7 2}: \mathrm{R}^{1}=\mathrm{Cl} ; \mathbf{7 3}: \mathrm{R}^{1}=\mathrm{Br}$

The reduction of unsymmetrical ketone to alcohols is one of the most common reactions in organic synthesis. During the reduction, nucleophile can approach both the faces of a carbonyl group of aryl-1-ethanones with an angle close to $109^{\circ}$ giving rise to a mixture of two isomers. The asymmetric metal complex catalysis is one of the fast developing fields of modern chemistry [48]. Not only academic but also ever growing practical and industrial interest prompts researchers to make more efforts to develop the catalytic synthesis of various enantiomerically pure 64, 71-73 [49]. It is mentioned that many research groups put most their efforts onto catalytic testings of ligands, for example for the separation of 64 via specific palladium catalysed oxidation [50]. On the other hand, the reduction of aryl-1-ethanones 19, 20, 35, 70 with complex sodium borohydride- $\beta$-cyclodextrin leads to enantio-enriched alcohols [51]. The epoxide 66 serves as a starting point in the synthesis of alcohols 67, 68 and 69 [47]. The last compound can be synthesized (yield $94 \%, 93$ ee) directly from 65 by hydroxylation using optically active catalyst [52].

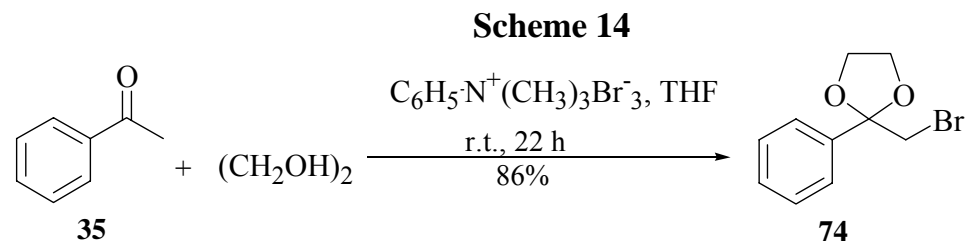

$\alpha$-Bromoketals are useful precursors in the synthesis of different organic compounds, including agrochemicals [53-56]. They can be readily prepared by a number of methods: 1) bromination of methylketones followed by protection of carbonyl group; 2) ketalization with 1,2-diols and then bromination; 3) when bromination and ketalisation going together. The synthesis of phenacylbromides as well as 1,3-dioxolanes has already been overviewed by us, and so just the one pot reaction for formation of $\alpha$-bromoketals will be discussed.

\section{Scheme 15}

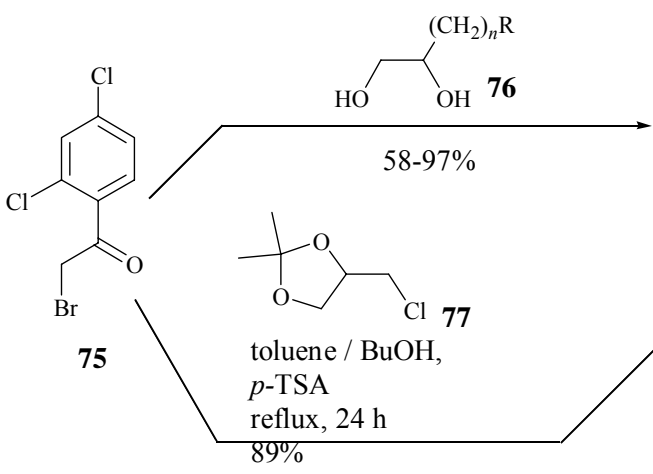

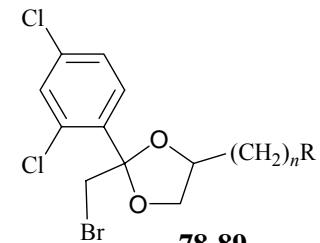

78-89

$78: \mathrm{R}=\mathrm{OTs}, \mathrm{n}=1 ; \mathbf{7 9}: \mathrm{R}=\mathrm{OH}, \mathrm{n}=1$;

$\mathbf{8 0}: \mathrm{R}=\mathrm{CO}_{2} \mathrm{H}, \mathrm{n}=1 ; \mathbf{8 1}: \mathrm{R}=\mathrm{Ph}, \mathrm{n}=0$;

$82: \mathrm{R}=2,4-\mathrm{Cl}_{2}-\mathrm{C}_{6} \mathrm{H}_{3}, \mathrm{n}=0 ; 83: \mathrm{R}=2,4-\mathrm{Cl}_{2}-\mathrm{C}_{6} \mathrm{H}_{3}, \mathrm{n}=1$

$84: \mathrm{R}=4-\mathrm{Cl}-\mathrm{C}_{6} \mathrm{H}_{4}, \mathrm{n}=1 ; 85: \mathrm{R}=2,4-\mathrm{C}_{6} \mathrm{H}_{3}, \mathrm{n}=2$

86: $\mathrm{R}=4-\mathrm{Cl}-\mathrm{C}_{6} \mathrm{H}_{4}, \mathrm{n}=0 ; 87: \mathrm{R}=4-\mathrm{Cl}-\mathrm{C}_{6} \mathrm{H}_{4}, \mathrm{n}=1$

88: $\mathrm{R}=4-\mathrm{Cl}-\mathrm{C}_{6} \mathrm{H}_{4}, \mathrm{n}=2 ; 89: \mathrm{R}=\mathrm{Cl}, \mathrm{n}=1$ 
Environmental and economical considerations prompt an urgent need to redesign there important processes. In this context, an example of preparation of 2-bromomethyl-2-phenyl-1,3-dioxolane 74 is presented on scheme 14 [57].

The related bromides 78-89 could be prepared in one step from 2-bromo-1-(2,4-dichlorophenyl)-1-ethanone 75 and 1,2dioles 76 [58]. It was established that the acetalization performs in the presence of $p$-toluenesulfonic acid in a mixture of 1-butanol - benzene. Notably, in absence of 1-butanol the reaction doesn't take place or the yields are usually low [59].

The separation of diastereomeric products $\mathbf{7 9}$ as well as $\mathbf{8 0}$ can be done by use of lipase [60].

The synthesis of optically active compounds $\mathbf{8 9}$ from R- and S-isomers of $\mathbf{7 7}$ was also carried out [55]. All the attempts of ketalization 75 with enantiomerically pure epichlohydrines by method [61] have been burst.

The convergent of total synthesis of $\left(2 R, 4 S, 2^{\prime} S, 3^{\prime} R\right)$-hydroxyitraconazole 95 was previously reported [62]. The described process includes the conversion of ketone $\mathbf{9 0}$ and 1,2-diol 91 to the corresponding acetonide 92 . Palladiumcatalyzed coupling of 93 with 94 followed by deprotection was burnished 95 .

\section{Scheme 16}
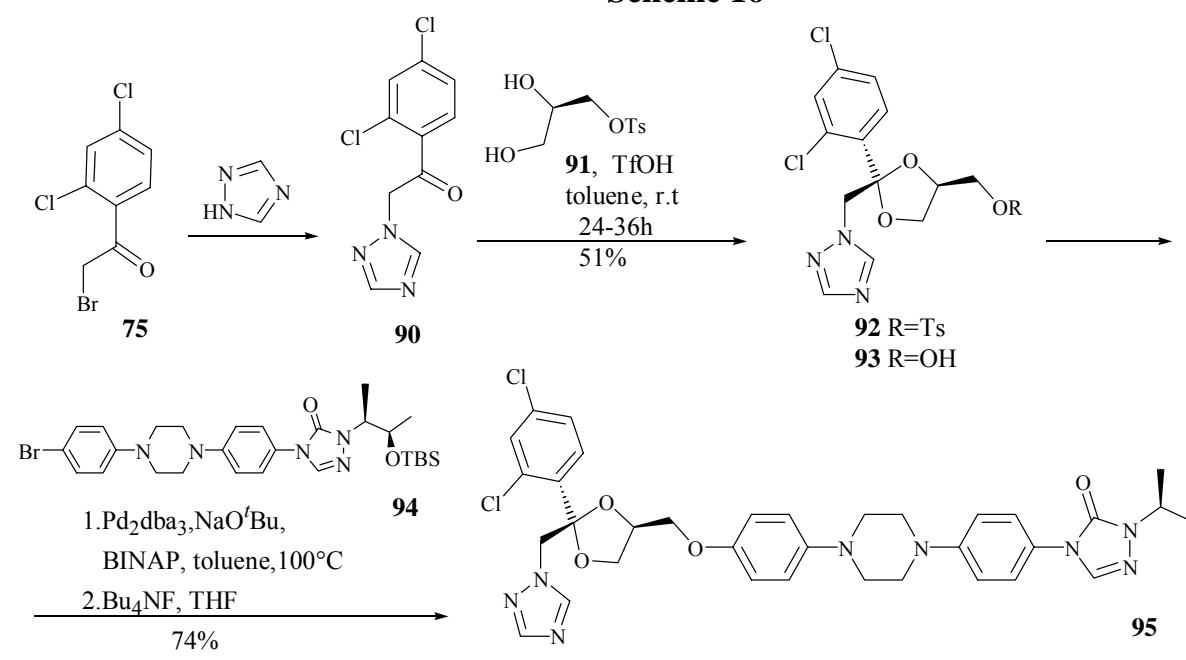

$93 \mathrm{R}=\mathrm{OH}$

\section{Synthetic schemes based on the products of primary transformation of acetyl group}

Heterocyclic compounds are the basis of many pharmaceutical, agrochemical and veterinary products. A large amount of references on synthetic methods of elaboration of heterocycle ring structures based on the products of primary transformation of the acetyl group of acetophenones were early summarized [1-3], however, time passes and new results have been published.

The selective transformation of bromohydrines 98, 99 obtained from 2-bromoacetophenones 37, 96 by chiral catalyst 97 reduction, to enantiomerically-pure epoxides 66 and 100 can be achieved by using $\mathrm{K}_{2} \mathrm{CO}_{3}$ as a base [63].

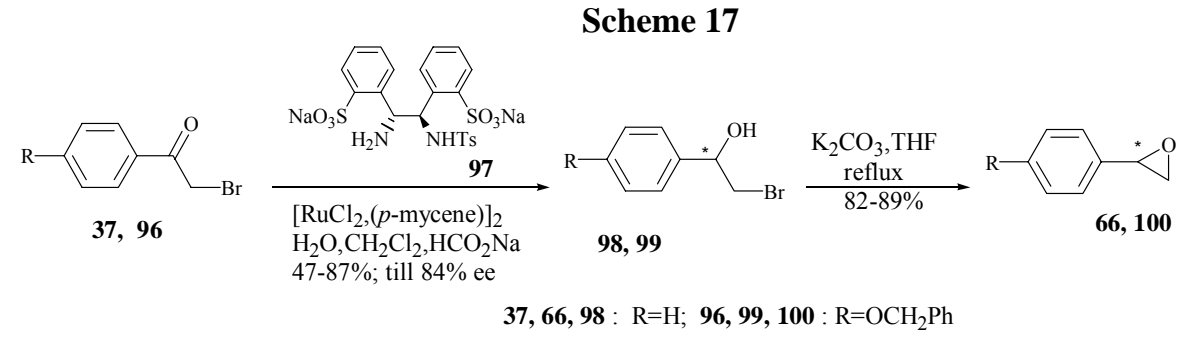

Chalcones still remain the subjects for the studing of structure-bioactivity properties [25,64,65], but most efforts involve the generation of functional chiral molecular diversity using their $\alpha, \beta$-unsaturated system as illustrated in Scheme 18 .<smiles>[R]C(CC(=O)c1ccccc1)c1ccccc1</smiles>

101-108

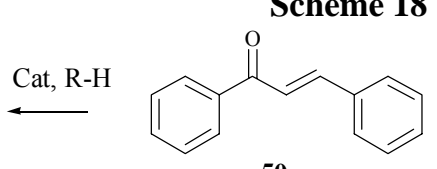

50

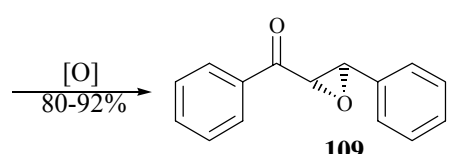

109

$101: \mathrm{R}=-\mathrm{CH}_{2} \mathrm{NO}_{2} ; 102: \mathrm{R}=\mathrm{C}(\mathrm{O})-\mathrm{CH}=\mathrm{CMe}_{2} ; 103: \mathrm{R}=\mathrm{C}(\mathrm{O})-\left(\mathrm{CH}_{2}\right)_{4} \mathrm{Me} ; 104: \mathrm{R}=\mathrm{C}(\mathrm{O})-3-\mathrm{Br}-\mathrm{C}_{6} \mathrm{H}_{4}$; $105: \mathrm{R}=\mathrm{CH}(\mathrm{Me})-\mathrm{C}(\mathrm{O})-\mathrm{Ph} ; 106: \mathrm{R}=\mathrm{CH}\left(\mathrm{CO}_{2} \mathrm{Et}\right)-\mathrm{COMe} ; 107: \mathrm{R}=\mathrm{CH}\left(\mathrm{CO}_{2} \mathrm{Et}\right)-\mathrm{COMe} ; 108: \mathrm{R}=\mathrm{H}$

For example, the synthesis of enantio-enriched (3S)-ketone 101 was based on the mediated asymmetric catalyst conjugated 1,4-addition reaction of $\mathrm{MeNO}_{2}$ to 50 [66]. The solvent-free microwave-induced reaction of 50 with wide range of aliphatic and aromatic aldehydes on the surface of $\mathrm{SiO}_{2}$ gave adducts 102-104 [67]. According to another 
report, lithium alkoxides was employed as a catalyst for the Michael addition of silyl enol ethers to 50 leading product 105 [68]. The reaction of acetoacetic ester with $\mathbf{5 0}$ in the presence of $\mathrm{K}_{2} \mathrm{CO}_{3}$ produced mixture stereo isomers 106, 107 [69]. Selective reduction of $\mathbf{5 0}$ to $\mathbf{1 0 8}$ as well as asymmetric epoxidation to $\mathbf{1 0 9}$ was reviewed recently [70], and published also [71,72].

Chalcone 50 was used as a model for the studing of possibility of synthesis of 1,2-dibenzoyl-3-methyl-3phenylcyclopropanes. It was found out that cyclopropanation by sulfur ilide, generated from salt 110, leads to a mixture of isomers 111, 112, although the selectivity in this reaction was not good [73].

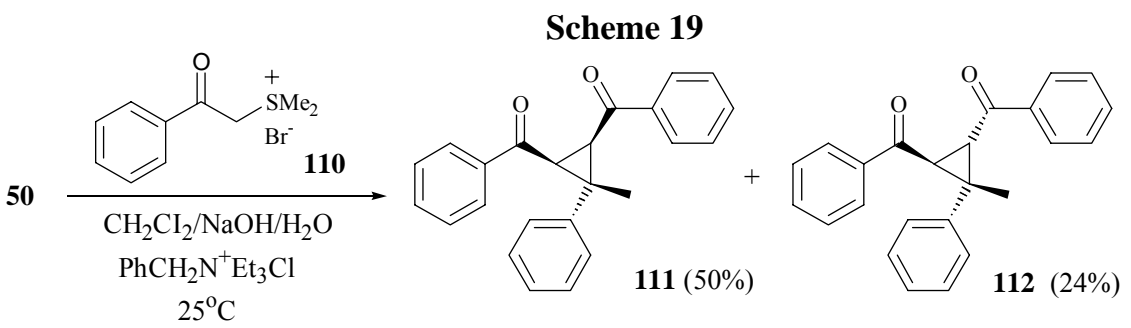

Dihydroisoxazoles 114 and dihydropyrazoles $\mathbf{1 1 5 - 1 1 9}$ can be prepared by the reaction of chalcones 113 with hydroxylamine, hydrazine hydrate, monosubstituted hydrazines, and thiosemicarbazide according scheme 20 [74-80].

Scheme 20

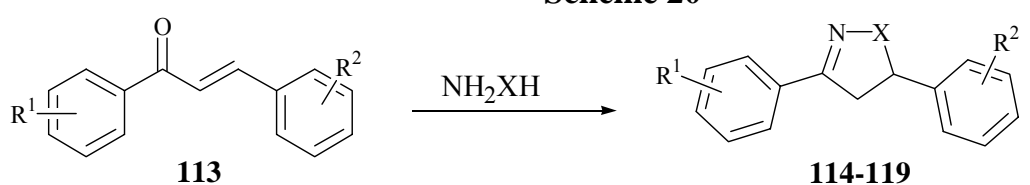

$114: \mathrm{X}=\mathrm{O} ; 115: \mathrm{X}=\mathrm{NH} ; 116: \mathrm{X}=\mathrm{NAr} ; 117: \mathrm{X}=\mathrm{NC}(\mathrm{S}) \mathrm{NH}_{2} ; 118: \mathrm{X}=\mathrm{Nalkyl} ; 119: \mathrm{X}=\mathrm{NAc}$

One pot synthesis of N-acetyl-substituted dihydropyrazoles 119 was carried out in AcOH [81,82]. 1,3,5-Triphenyl-4,5dihydro- $1 H$-pyrazoles 116 can be prepared it two steps from chalcones 113 and phenyl hydrazine via hydrazone followed by the heterocyclization in boiling acetic acid. The influence of nature of the substituent in chalcone's ring on isolation of intermediate hydrazone is discussed [83]. Formation of N-carbamoyl, N-carbonyl as well as N-sulfanyl dihydropyrazoles by reaction with polymer-bound reagents was also described [84]. Synthesis of 3,5-diaryl-Nalkyldihydropyrazoles 118 from 3,5-diaryldihydropyrazoles 115 can be done by use of the phase transfer catalysis reaction [85]. Some derivatives of 3,5-diaryl-2- dihydropyrazoles 114 and 1,3,5-triphenyl-2-dihydropyrazoles 116 were found to exhibit the antidepressant activity [78,79].

4-Substituted dihydroizoxazole 121 and dihydropyrazoles 122, 123 were prepared from oxides 120 or dibromides 124 (Scheme 21) [2,86].

\section{Scheme 21}

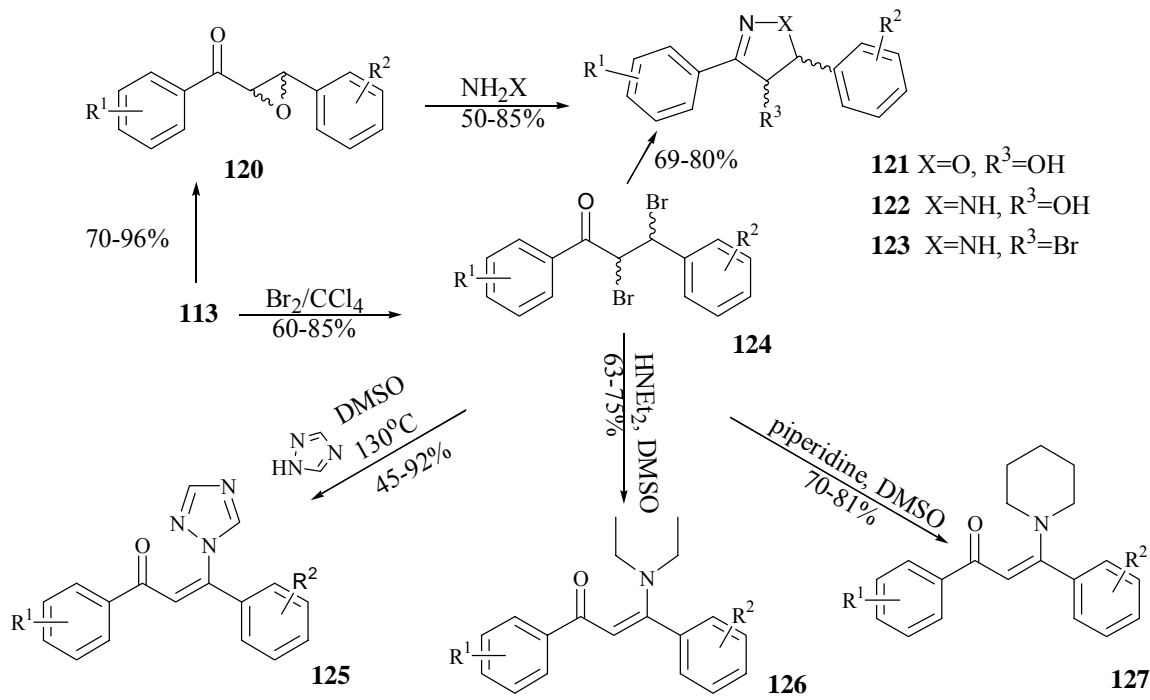

Compounds 121-123 represent an unstable mixture of isomers resulting diphenylisoxazoles and diphenylpyrazoles. The treatment of the 124 with secondary amines furnished enamines 125-127 [87,88]. 
Antimicrobial agents 129a-c have to be synthesized by reaction of 1-aryl-3-(5-aryl-2-furyl)-2-propen-1-ones 128a-c with hydrazine hydrate or phenyl hydrazine [89].

\section{Scheme 22}<smiles>[R]c1ccc(C(=O)/C=C/c2ccc(-c3ccc([R])cc3)o2)cc1</smiles><smiles>[R]c1ccc(C2=NN([Y])C(c3ccc(-c4ccc([R])cc4)o3)C2)cc1</smiles>

a: $\mathrm{R}^{1}=\mathrm{NO}_{2}, \mathrm{R}^{2}=\mathrm{Cl}, \mathrm{R}^{3}=\mathrm{H} ; \mathbf{b}: \mathrm{R}^{1}=\mathrm{Cl}, \mathrm{R}^{2}=\mathrm{H}, \mathrm{R}^{3}=\mathrm{Ph} ; \mathbf{c}: \mathrm{R}^{1}=\mathrm{Br}, \mathrm{R}^{2}=\mathrm{Me}, \mathrm{R}^{3}=\mathrm{H}$

The stead of spiran stems among natural and synthetic products arouses a great interest in there. A special position among these compounds is occupied by spiro-indolin-2-ones. There are many methods of synthesis of such type derivatives, which are discussed in review [90].

$\alpha, \beta$-Unsaturated ketone 54 can be readily transformed into spiro-products 130 and 133 upon treatment with hydroxylamine, hydrazine hydrate [74,91,92].

\section{Scheme 23}

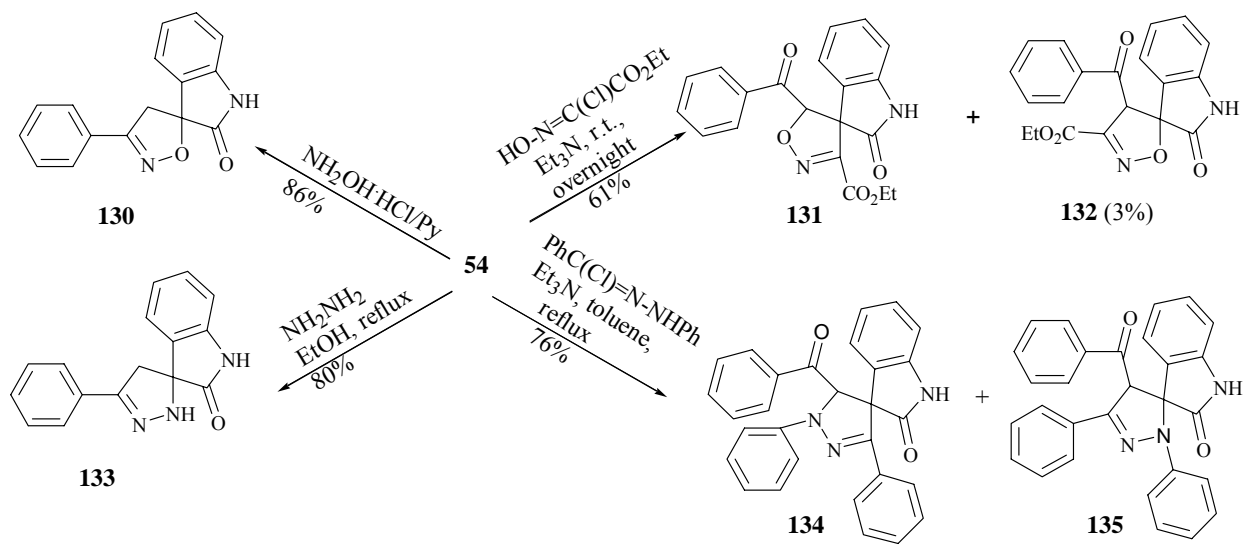

Regioselective cycloaddition of carboethoxyformonitrile oxide (generated in situ from hydroxamoyl chloride) to 54 could be regarded as one of the approaches to spiroproducts 131 [93]. The content of regioisomer 132 is not more than $3 \%$. The same author reported the synthesis of mixture of $\mathbf{1 3 4}$ and 135.

The syntheses of organic compounds starting from $\alpha$-halogeno ketones were overviewed [3,94]. Based on this information, new data for the synthesis of heterocyclic systems will be reviewed. For example, N-substituted 2aminothiazoles 136 are synthesized in one-pot procedure using 38 and amines (Scheme 24) [95].

Scheme 24<smiles>[R]Nc1nc(-c2ccc([N+](=O)[O-])cc2)cs1</smiles>

Selectivity of the reaction decreases for $\alpha, \alpha$-disubstituted amines, and with $\alpha, \alpha, \alpha$ '-trisubstituted amines no reaction occurs. Only ethanol proved to be a suitable solvent for the described above transformation; the yield of target compound was very poor in DMF or acetonitrile.

Authors [96] have reported the solid support synthesis of 2,4-disubstituted aminothiazoles. Rink amide resin with loaded 3-iodobenzoic acid was involved in $\mathrm{Pd}(0)$ coupling reaction with tributyl(1-ethoxyvinyl)tin followed by bromination leads to bromoketones. Last were condensed with thiourea and thioamide, followed by trifluoroacetic acid cleavage from resin, to give targets 137 a-e (total yields $61-90 \%$ ). 


\section{Scheme 25}

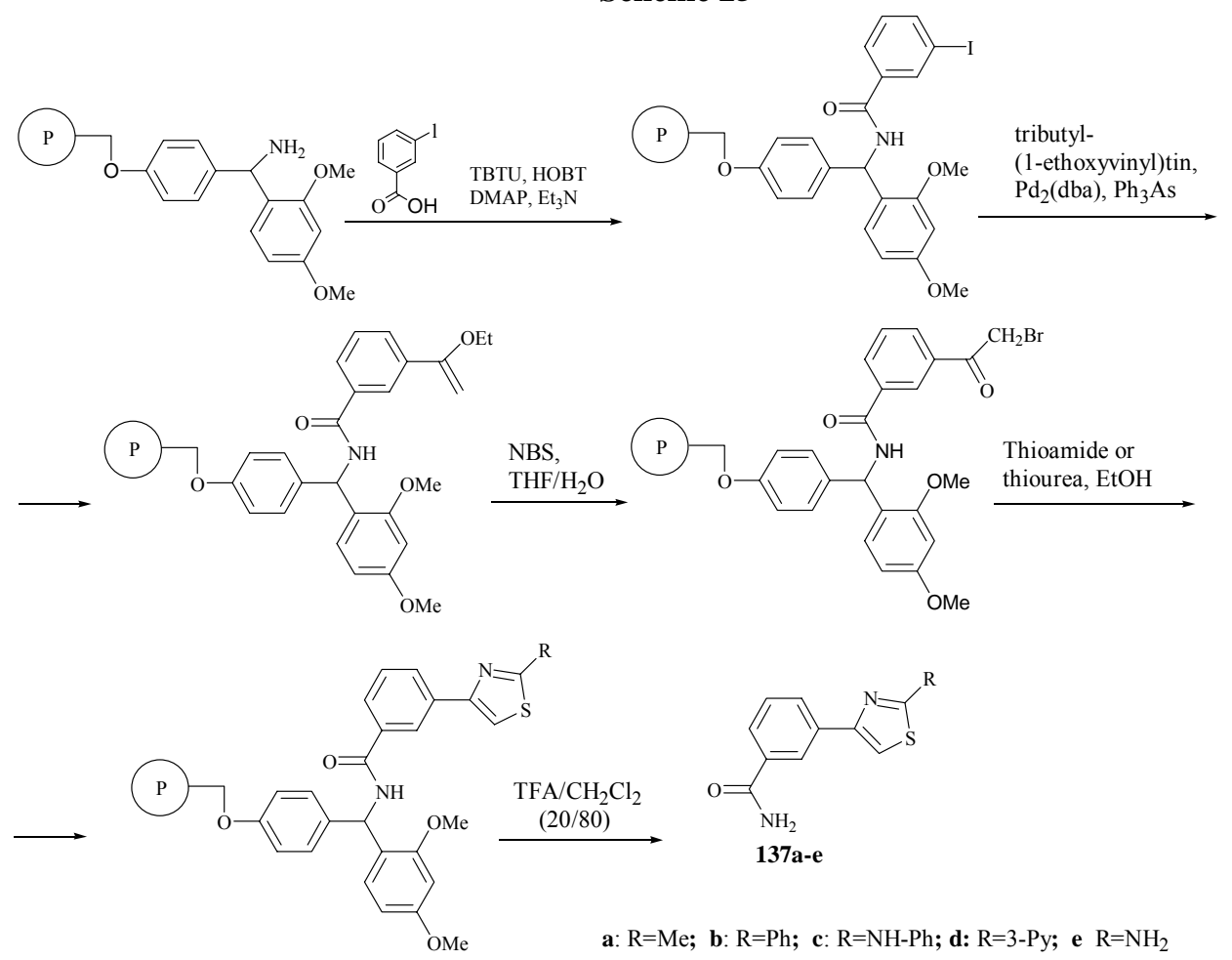

2-Aminothiazole 139 was obtained from the 37 in one-pot reaction, using supported reagents systems $\mathrm{KSCN} / \mathrm{SiO}_{2}$ $\mathrm{NH}_{4} \mathrm{Oac} / \mathrm{Al}_{2} \mathrm{O}_{3}$ (Scheme 26) [97].

\section{Scheme 26}
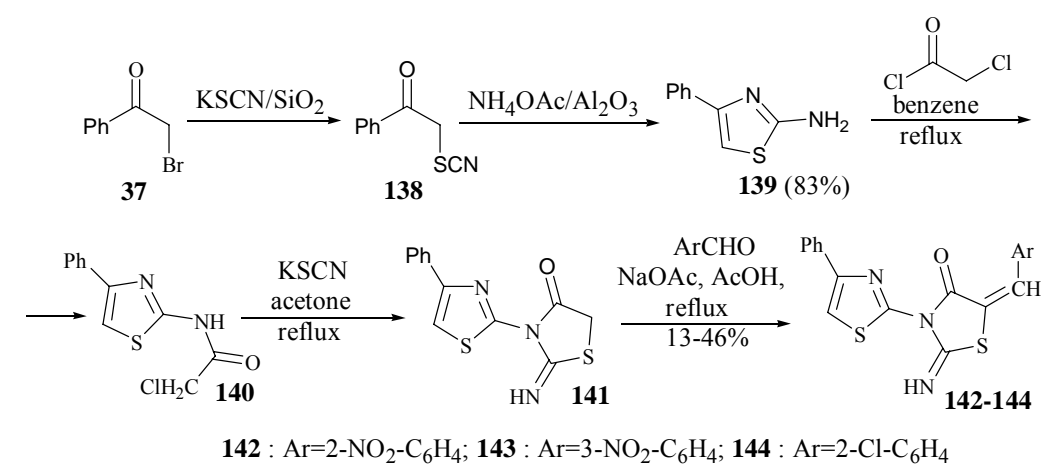

First, 2'-bromoacetophenone 37 reacts with $\mathrm{KSCN} / \mathrm{SiO}_{2}$, and then the obtained $\alpha$-thiocyanatoketone 138 reacts with $\mathrm{NH}_{4} \mathrm{Oac} / \mathrm{Al}_{2} \mathrm{O}_{3}$ to afford final product 139. Fungicides 142-144 could be prepared via aminothiazoles 140, 141 [98].

As a new variant of Hantzsch thiazole synthesis, the reactions of 1-alkyl-2-thiobiureas 145 with 2-bromo-1-phenyl-1ethanone 37 yielded 3-alkyl-4-aryl-2-semicarbazono- $\Delta^{4}$-dihydrothiazoles 146a,b was presented [99].

Scheme 27

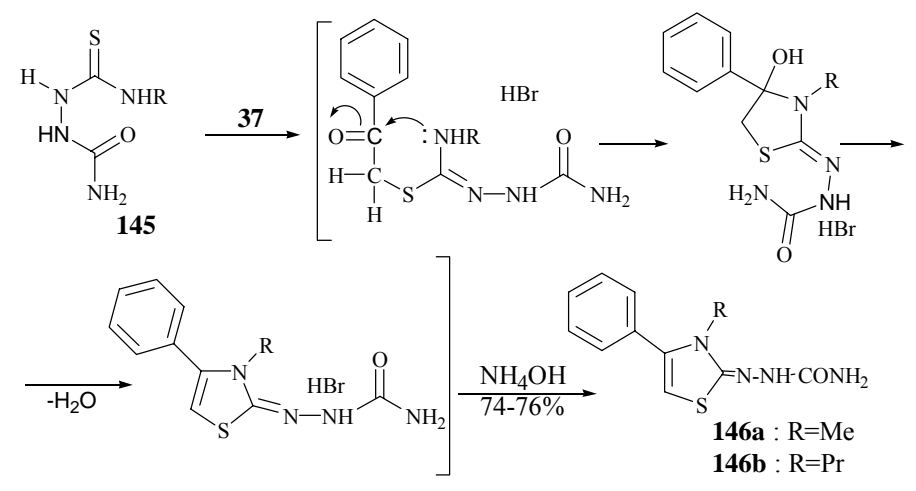


The combinatoric method for synthesis the molecular libraries of 2-aminothiazoles 149-153 is based on use of DMF as a solvent and dimethylamine as acceptor of $\mathrm{HBr}[100]$.

\section{Scheme 28}

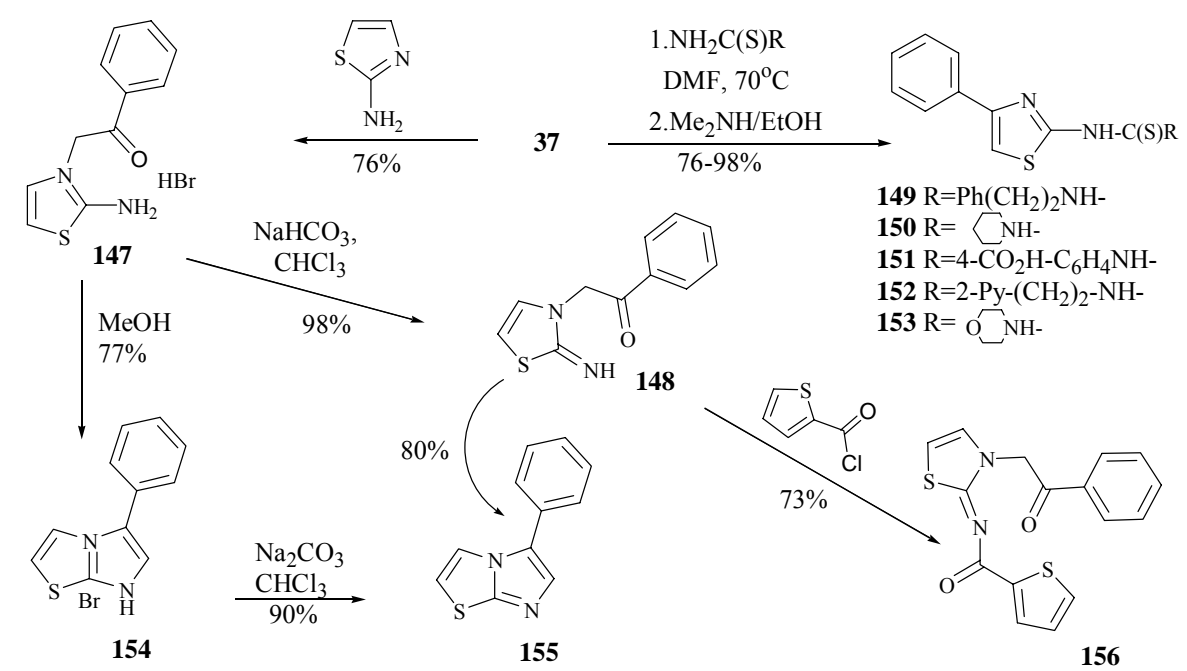

The imidazo[2,1-b]thiazoles $\mathbf{1 5 4 , 1 5 5}$ were prepared from 2-aminothiazole and 37 [101]. The adduct 147 was used for the synthesis of ketones 148, 156.

We established that 2-amino-1-arylideneaminoimidazoles 158 and 1-arylideneaminoimidazo[1,2-a]imidazoles 159 can be synthesized through combination of hydrazones 157 as well as 2-bromo-1-aryl-1-ethanones [102].

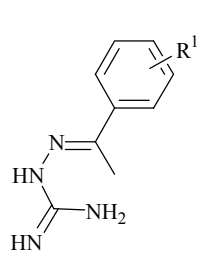

157

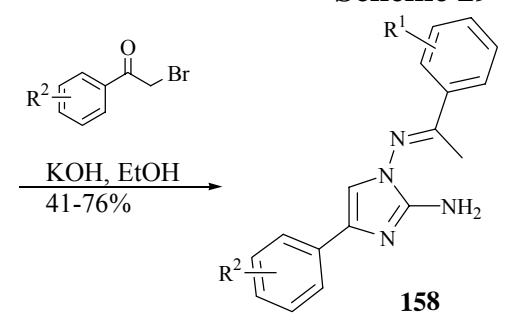

158

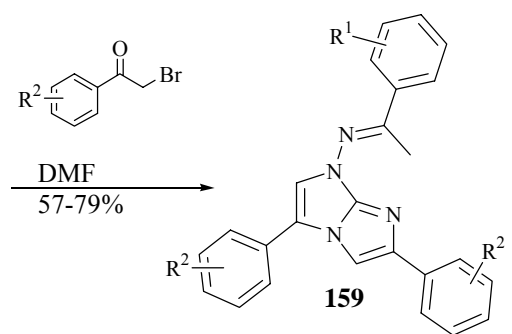

One-pot procedure for the rapid synthesis of 5,11-dioxa- and 5-oxa-11-thiabenzo[b]fluoren-10-ones 162a,b via condensation of esters of salicylic and thio-salicylic acids 160a,b with $\alpha$-bromoketone 161 was discovered [103].

\section{Scheme 30}

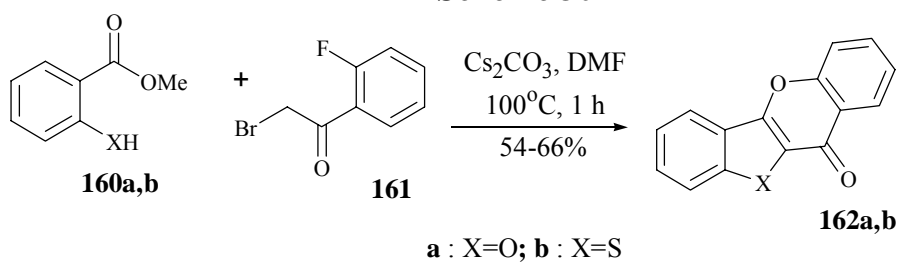

The preparation of 1,2,4-triazolechlorohydrine $\mathbf{1 6 6}$ has involved three step process transformation of chloroketone $\mathbf{1 6 3}$ via alkynes 164, 165 as illustrated in Scheme 31 [103].

Scheme 31

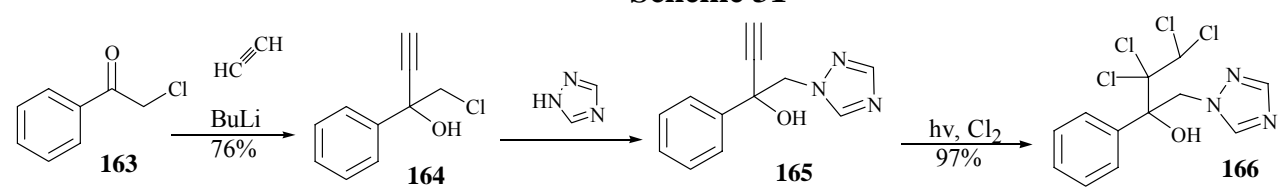

We reported our efforts to find the relationship of the bioactivity from the nature of substituents in 1,2,4-triazoles 167$178[104,105]$. Condensation of ketone 90 and aldehydes (Knoevenagel reaction) gives the specific formation of $Z$ isomer of N-vinyl-1,2,4-triazoles 171-177. Synthesized allylic alcohols 178-184 and its precursors exhibit anti-fungal and anti-bacterial activity. The selective synthesis of 2,4-bis(azolylmethyl)-2-(2,4-dichlorophenyl)-1,3-dioxolanes 169, $\mathbf{1 7 0}$ has to be carried out via preliminary preparation of alcohols 167 and corresponding mesylates 168 [59]. 
Scheme 32
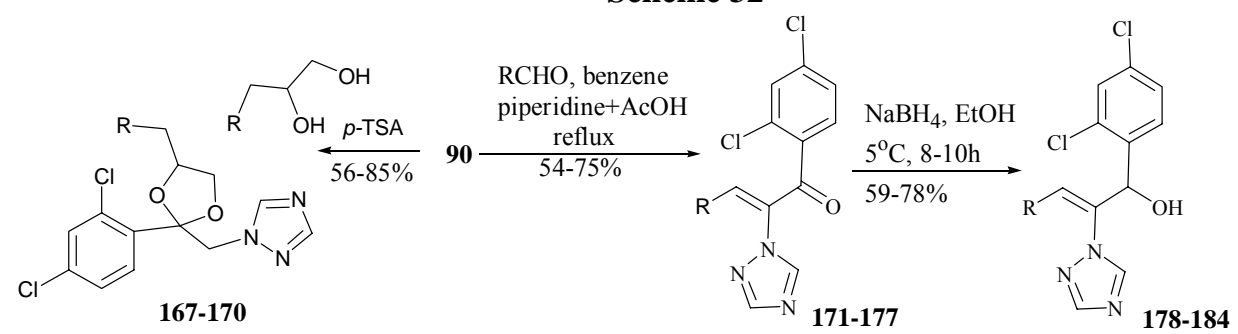

$167: \mathrm{R}=\mathrm{OH} ; 168: \mathrm{R}=\mathrm{OMs} ; 169: \mathrm{R}=-1,2,4-\mathrm{Tr} ; 170: \mathrm{R}=\mathrm{Im} ; 171,178: \mathrm{R}=-n-\mathrm{C}_{3} \mathrm{H}_{7} ; 172,179: \mathrm{R}=-i-\mathrm{C}_{3} \mathrm{H}_{7}$;

173, $180: \mathrm{R}=-n-\mathrm{C}_{4} \mathrm{H}_{9} ; 174,181: \mathrm{R}=-i-\mathrm{C}_{4} \mathrm{H}_{9} ; 175,182: \mathrm{R}=-3-\mathrm{Py} ; 176,183: \mathrm{R}=-\mathrm{Ph} ; 177,184: \mathrm{R}=-4-\mathrm{Cl}-\mathrm{C}_{6} \mathrm{H}_{4}$

The computer-aided study "structure-activity" of synthesized compounds was also reported [106].

Recently, we have select 2-bromo-1-(4-halogenophenyl)-1-ethanones 29, 185 as an intermediates for the synthesis of new anxiolytics 186, 187 (Scheme 33) [107].

\section{Scheme 33}

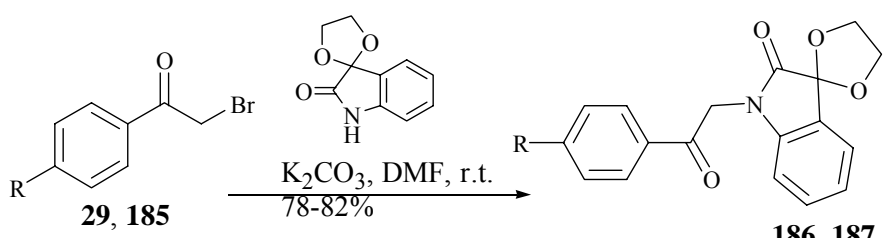

29, $186: \mathrm{R}=\mathrm{Br} ; 185,187: \mathrm{R}=\mathrm{F}$

Also, a series of 2,5-disubstituted-1,3,4-thiadiazoles 188-192 aws designed and synthesized, and these compounds were screened for anti-tuberculosis activity against Mycobacterium tuberculosis H37Rv [108].

Scheme 34
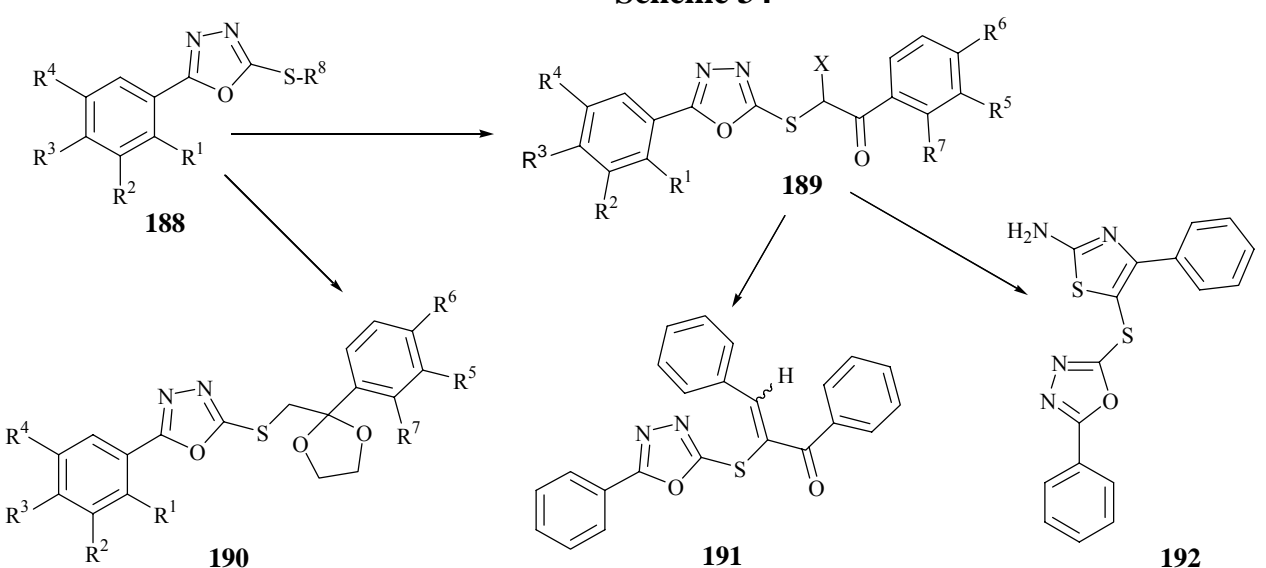

It was found that 1,3-dioxolane derivatives 190 are less active than the corresponding keto-precursor compounds 189. Compound $190\left(\mathrm{R}^{1}=\mathrm{R}^{2}=\mathrm{R}^{3}=\mathrm{R}^{4}=\mathrm{R}^{5}=\mathrm{R}^{6}=\mathrm{R}^{7}=\mathrm{H}\right)$ is a notable exception. The last compound showed the highest target activity (82\%) among all the 5-aryl-2-thio-1,3,4-oxadiazoles.

\section{Conclusions}

The present compilation showed clearly the diversity in the field of synthetic organic chemistry by use of the acetyl group of aryl-1-ethanones. In the future, more complex target compounds, new methodology will be required for rapid construction of molecules bearing unusual substitution patterns. Thus, work is being continued in an effort to elucidate innovative new regio-, stereo- and enantio-selectively processes using the acetophenones to obtain products with target properties.

\section{Acknowledgments}

I would like to thank my co-workers for their suggestions which made better this paper as well as our research. Their names are listed in the references.

\section{References}

[1] Desenko, S.M.; Orlov, V. D. Azoheterocycles on bases unsaturated aromatic ketones. Folio, Char'kov, 1998. 
[2] Dhar, D. N. The chemistry of chalcones and related compounds. A wiley-interscience publication, New York, 1981.

[3] Erian, A. W.; Sherif, S. M.; Gaber, H. M. Molecules, 2003, 8, 793-865.

[4] Moiseev, I. K.; Zentsova, M. N.; Makarova, N. V. Khim. Geter. Soedin. 1994, 7, 867-885.

[5] Livantsov, M.V.. Sorosovskii obrazovatelinii zurnal. 2001, 5, 51-57.

[6] Kawabata, T.; Mizugaki, T.; Ebitani, K.; Kaneda, K. Tetrahedron Lett. 2001, 42, 8329-8332.

[7] Ballini, R.; Bosica, G.; Frullanti, B.; Maggi, R.; Sartori, G.; Schroer, F. Tetrahedron Lett. 1998, 39, 1615-1618.

[8] Ponde, D.; Borate, H. B.; Sudalai, A.; Ravindranathan, T.; Deshpande, V. H. Tetrahedron Lett. 1996, 37, 46054608.

[9] Shun-Jun, Ji; Lin, Wu. J. Mol. Cat. A. 2001, 202, 41-46.

[10] Caputo, R.; Ferreti, C.; Palumbo, G. Synthesis. 1987, 4, 386-389.

[11] Lukacs, G.; Porcs-Makkay, M.; Simig, G. Tetrahedron Lett. 2003, 44, 3211-3214.

[12] Casas, J. S.; Garcya-Tasende, M. S.; Sordo, J. Coord. Chem. Rev. 2000, 209, 197-261.

[13] John, R. P.; Sreekanth, A.; Kurup, M. R. P.; Usman, A.; Ibrahim, A. R.; Fun, H.K. Spect. Chim. Acta: A. 2003, 59, 1349-1358.

[14] Lobana, T. S.; Casas, J. S.; Castineiras, A.; Garcya-Tasende, M. S.; Sanchez, A.; Sordo, J. Inorg. Chim. Acta. 2003, 347, 23-32.

[15] John, R. P.; Sreekanth, A.; Kupur, M. R. P.; Mobin, S. M. Polyhedron. 2002, 21, 2515-2521.

[16] Paul, S.; Gupta, V.; Loupy, A. Tetrahedron Lett. 2003, 44, 439-442.

[17] King, L. C.; Ostrum, G. K. J. Org. Chem. 1964, 29, 3459-3461.

[18] Zavi’ealov, S. I.; Ejova, Gh. I.; Sitkareva, I. V.; Dorofeeva, O. V.; Zagozin, A. Gh.; Rumeantseva, E.E. Izv. AN SSSR, Ser. Khim. 1989, 10, 2392.

[19] Rodighin, M. Yu.; Michailov, V. A.; Savelova V. A. Russ. J. Org. Chem. (Engl.Transl.) 1994, $30,827-832$.

[20] Forlani, L. Synthesis. 1980, 6, 487-489.

[21] Magen, S.; Oren, J.; Fuchs, B. Tetrahedron Lett. 1984, 25, 3369-3372.

[22] Cacchi, S.; Caglioti, L. Synthesis. 1979, 1, 64-67.

[23] Adhikari, M. V.; Samant, S. D. Ultr. Sonochem. 2002, 9, 107-111.

[24] Iinuma M., Mizuno M. Phytochemistry. 1989, 28, 681-694.

[25] Meng, C. Q.; Zheng, X. S.; Ni, L.; Ye, Z.; Simpson, J. E.; Worsencroft, K. J.; Hotema, M. R.; Weingarten, M. D.; Skudlarek, J. W.; Gilmore, J. M.; Hoong, L. K.; Hill, R. R.; Marino, E. M.; Suen, K.L.; Kunsch, C.;

Wasserman, M. A.; Sikorski, J. A. Bioorg. Med. Chem. Lett. 2004, 14, 1513-1517.

[26] Edwards, M. L.; Stemerick, D.M.; Sunkara, P.S. J. Med. Chem. 1990, 33, 1948-1954.

[27] Barron, D.; Ibrahimt, R. K. Phytochemistry. 1996, 43, 5, 921-982.

[28] Cook, J.; Samman, G. J. Nutr. Biochem. 1996, 7, 67-76.

[29] Filler, R.; Beaucaire, V. D.; Kang, H. H. J. Org. Chem. 1975, 40, 935-939.

[30] Noyce, D. S.; Pryor, W. A. J. Am. Chem. Soc. 1955, 77, 1397-1401.

[31] Wagman, A. S.; Wang, L.; Nuss J. M. J. Org. Chem. 2000, 65, 9103-9113.

[32] Cravotto, G.; Demetri, A.; Nano, G. M.; Palmisano, G.; Penoni, A.; Tagliapietra, S. Eur. J. Org. Chem. 2003, 4438-4444.

[33] Li, J. T.; Yang, W. Z.; Wang, S.X.; Li, S. H.; Li, T.S. Ultr. Sonochem. 2002, 9, 237-238.

[34] Joshi, K. C.; Dandia, A.; Bhagat, S. J. Indian Chem. Soc. 1990, 67, 753-756.

[35] Woodard, C. L.; Li, Z.; Kathcart, A. K.; Terrell, J.; Gerena, L.; Lopez-Sanchez, M.; Kyle, D. E.; Bhattacharjee, A. K.; Nichols, D. A.; Ellis, W.; Prigge, S. T.; Geyer, J. A.; Waters, N. C. J. Med. Chem. 2003, 46, 3877-3882.

[36] Lee, T. V.; Toczek, J. Tetrahedron Lett. 1982, 23, 2917-2920.

[37] Rubottom, G. M.; Vazquez, M. A.; Pelegrina, D. R. Tetrahedron Lett. 1974, 49-50, 4319-4322.

[38] Moriarty, R. M.; Prakash, O.; Duncan, M. P. Synthesis. 1985, 10, 943-944.

[39] Hassner, A.; Reuss, R. H.; Pinnick, H. W. J. Org. Chem. 1975, 40, 3427-3429.

[40] Moriarty, R. M.; Hou, K. Ch. Tetrahedron Lett. 1984, 25, 691-694.

[41] Moriarty, R. M.; Hu, H.; Gupta, S. C. Tetrahedron Lett. 1981, 22, 1283-1286.

[42] Lenke, K.; Theil, F.; Kunath, A.; Schick, H. Tetrahedron: Asymmetry. 1996, 7, 971-974.

[43] Chang, H. T.; Sharpless, K. B. Tetrahedron Lett. 1996, 37, 3219-3222.

[44] Hanzlik, R. P.; Shearer, G. O. J. Am. Chem. Soc. 1975, 97, 5231-5233.

[45] Palucki, M.; Pospisil, P. J.; Zhang, W.; Jacobsen, E. N. J. Am. Chem. Soc. 1994, 116, 9333-9334.

[46] Fung, W. H.; Yu, W. Y.; Che, C. M. J. Org. Chem. 1998, 63, 7715-7726.

[47] Capriati, V.; Florio, S.; Luisi, R.; Salomone, A. Org. Lett. 2002, 4, 2445-2448.

[48] Pavlov, V. A. Russ. Chem. Rev. (Engl.Transl.) 2001, 70, 1037-1065.

[49] Ghlushkov, V. A.; Tolstikov, A. Gh. Russ. Chem. Rev. (Engl.Transl.) 2004, 73, 581-608.

[50] Stoltz, B. M. Chemistry lett. 2004, 4, 362-366.

[51] Doussot, J.; Guy, A.; Garreau, R.; Falguieres, A.; Cossy, J.; Amsterdamsky, C. Bull. Soc. Chim. Fr. 1996, 133, 161-165.

[52] Huang, J.; Corey, E. J. Org. Lett. 2003, 5, 3455-3461.

[53] Sekimata, K.; Han, S. Y.; Yoneyama, K.; Takeuchi, Y.; Yoshida, S.; Asami, T. J. Agric. Food Chem. 2002, 50, 3486-3490. 
[54] Sekimata, K.; Uzawa, J.; Han, S. Y.; Yoneyama, K.; Takeuchi, Y.; Yoshida, S.; Asami, T. Tetrahedron: Asymmetry. 2002, 13, 1875-1878.

[55] Camps, P.; Farres, X. Tetrahedron: Asymmetry. 1995, 6, 1283-1294.

[56] Meli'nikov, N. N. Pesticides. Khimiya, Moscow, 1987

[57] Visweswariah, S.; Prakash, G.; Bhushan, V.; Chandrasekaran, S. Synthesis. 1982, 4, 309-310.

[58] Heeres, J.; Cutsem, J. V. J. Med. Chem. 1981, 24, 1360-1364.

[59] Krimer, M. Z.; Stingaci, E. P. Bul. Acad. Stiint. Mold. Ser. Biol. Chim. Agr. 1994, 2, p.55-58.

[60] Kim, Y. H.; Cheong, C. S.; Lee, S. H.; Jun, S. J.; Kimb, K. S.; Cho, H. S. Tetrahedron: Asymmetry. 2002, 13, 2501-2508.

[61] Canpolat, E.; Kaya, M.; Gorgulu, M. Polish J. Chem. 2002, 76, 687-694.

[62] Tanoury, G.J.; Hett, R.; Wilkinson, H. S.; Wald, S. A.; Senanayake, C. H. Tetrahedron: Asymmetry. 2003, 14, 3487-3493.

[63] Ma, Y.; Liu, H.; Chen, L.; Cui, X.; Zhu, J.; Deng, J. Org. lett. 2003, 5, 2103-2106.

[64] Lin, Y. M.; Zhou, Y., Flavin, M. T., Zhou, L. M., Nie, W., Chen, F. C. Bioorg. Med. Chem. 2002, 10, $2795-2802$.

[65] Macaev, F.; Vlad, L.; Pogrebnoi, S.; Gudima, A. International conference "Chemistry, structure and function of molecules". Minsk, 2004. P.121.

[66] Funabashi, K.; Saida, Y.; Kanai, M.; Arai, T.; Sasai, H.; Shibasaki, M. Tetrahedron Lett. 1998, $39,7557-7558$.

[67] Yadav, J. S.; Anuradha, K.; Reddy, B. V. S.; Eeshwaraiah, B. Tetrahedron Lett. 2003, 44, 8959-8962.

[68] Mukaiyama, T.; Tozawa, T.; Fujisawa, H. Chem. Lett. 2004, 33, 1410-1411.

[69] Zhang, Z.; Dong, Y. W.; Wang, G. W., Komatsu, K. Chem. Lett. 2004, 33, 168-169.

[70] Bonini, C.; Righi, G. Tetrahedron. 2002, 58, 4981-5021.

[71] Adam, W.; Rao, P. B.; Degen, H. G.; Saha-Möller, C. R. J. Am. Chem. Soc., 2000, 122, 5654-5655.

[72] Arai, S.; Tsuge, H.; Shioiri, T. Tetrahedron Lett. 1998, 39, p.7563-7566.

[73] Reddy, D. B.; Reddy, B. V.; Seshamma, T.; Reddy, N. B.; Reddy, M. V. R. Synthesis.1989, 4, $289-290$.

[74] Stanovnik, B.; Svete, J. Science of Synthesis. 2002, 12, 15-37.

[75] Chimenti, F.; Bolasco, A.; Manna, F.; Secci, D.; Chimenti, P.; Befani, O.; Turini, P.; Giovannini, V.; Mondovy, B.; Cirilli, R.; Torre, F. J. Med. Chem. 2004, 47, 2071-2079.

[76] El-Hashash, M. A.; Soliman, F. M. A.; Souka, L. M.; Salman, A. S. S. Rev. Roum. Chim. 1995, 40, 59-65.

[77] Bayoumy, B. E.; El-Bahie, S.; El-Latif, G. A. Rev. Roum. Chim. 1993, 38, 701-707.

[78] Palaska, E.; Erol, D.; Demirdamar, R. Eur. J. Med. Chem. 1996, 31, 43-47.

[79] Palaska, E.; Aytemir, M.; Uzbay, G. T.; Erol, D. Eur. J. Med. Chem. 2001, 36, 539-543.

[80] Turan-Zitouni, G.; Chevallet, P.; Kilic, F. S.; Erol, K. Eur. J. Med. Chem. 2000, 35, 635-641.

[81] Macaev, F. Z.; Pogrebnoi, S. I.; Vlad, L.A.; Stingaci, E. P. Bul. Acad. Stiint. Mold. Ser. Biol. Chim. Agr. 2003, 2 , 124-127.

[82] a) Pogrebnoi, S., Ph.D. Thesis, Institute of Chemistry of the Academy of Science of Moldova, 2006.; b) Manna, F.; Chimenti, F.; Bolasco, A.; Secci, D.; Bizzarri, B.; Befani, O.; Turini, P.; Mondovi, B.; Alcaroc, S.; Tad, A. Bioorg. Med. Chem. Lett. 2002, 12, 3629-3631.

[83] Latif, N.; Mishriky, N.; Basyouni, W. Heterocycles. 1984, 21, 459-467.

[84] Bauer, U.; Egner, B. J.; Nilsson, I.; Berghult, M. Tetrahedron Lett. 2000, 41, 2713-2715.

[85] Pathak, V. N.; Pathak, R.; Oza, C. K. Indian J. Heterocycl. Chem. 1995, 5, 103-107.

[86] Saleh, R. M.; Soliman, A. Y.; Soliman, F. M. A. Rev. Roum. Chim. 1991, 36, 1337-1343.

[87] Rehter, M. A.; Ghrushetska'ea, Gh. N.; Panasenko, A. A.; Krimer, M. Z. Khim. Geter. Soedin. 1995, 7, 910-914.

[88] Gudima, A.; Pogrebnoi, S.; Pogrebnoi, I.; Barba, A.; Panasenko, A.; Vlad, L.; Stingaci, E.; Macaev, F. Anal. Univers. Stat Mold. Ser. Chim. Biol. 2002, 322-323.

[89] Holla, B. S.; Akberali, P. M.; Shivamanda, M. K. Il Farmaco. 2000, 55, 256-263.

[90] Macaev, F. Synthesis of spiroindolin-2-ones from $1 H$-indole-2,3-dione in Selected methods for synthesis and modification of heterocycles. Vol. 3 "The chemistry of synthetic indole systems". IBS press, Moscow. 2004, 75102.

[91] Mogilaiah, K., Babu, R. R. Indian J. Chem. 1998, 37B, 139-143.

[92] Jain, S. C.; Bhagat, S.; Rajwanshi, V. K.; Babu, B. R.; Sinha, J. J. Indian Chem. Soc. 1997, 36B, $633-639$.

[93] El-Ahl, A. A. S. Polish J. Chem. 1996, 70, 27-28.

[94] Moiseev, I. K.; Zemtsova, M. N.; Makarova, N. V. Khim. Geter. Soedin. 1994, 7, 867-885.

[95] Joachim, R. Tetrahedron. 2000, 56, 3161-3165.

[96] Kazzouli, S. El.; Berteina-Raboin, S.; Mouaddib, A.; Guillaument, G. Tetrahedron Lett. 2002, 43, 3193-3196.

[97] Kodomori, M.; Aoyama, T.; Suzuki, Y. Tetrahedron Lett. 2002, 43, 1717-1720.

[98] Liu, H.; Li, Z.; Anthonsen, T. Molecules. 2000, 5, 1055-1061.

[99] Suni, M. M.; Vipin, A. N.; Joshua, C. P. Tetrahedron Lett. 2001, 42, 97-99.

[100] Bailey, N.; Dean, A. W.; Judd, D. B., Middlemiss, D.; Storer, R.; Watson, S. P. Bioorg. Med. Chem. Lett. 1996, $6,1409-1414$

[101] Meakins, G. D.; Musk, S. R. R.; Robertson, C. A.; Woodhouse, L.S. J. Chem. Soc. Perkin Trans I. 1989, 643648.

[102] Krimer, M. Z.; Macaev, F. Z.; Stingaci, E. P.; Koretskii, A. Gh.; Pogrebnoi, S. I.; Cociuc, A. I. Khim. Geter. Soedin. 1996, 9, 1209-1213. 
[103] Patent. 4100516 Germany. Referat. J. Khim. 1993, 7, O392.

[104] a) F.Z. Macaev, E.P. Stingach, M.Z. Krimer. The first international conference "Chemistry and bioactivity of nitrogen containing heterocycles and alkaloids”. Moscow, 2001, 2, 294.; b) Krimer, M. Z.; Stingaci, E. P.; Rechter, M. A; Ghrushetska'ea, Gh. N. Ujavka, Z. N., Panasenko, A. A. Zinovi’eva, L. A., Minkin, V. I.; Abelentsev, V. A. Bul. Acad. Stiint. Mold. Ser. Biol. Chim. Agr. 1994, 1, 60-64.

[105] a) Macaev F.Z.; Stingaci, E.P.; Pogrebnoi, S. Substituted N-vinyl-1,2,4-triazoles in "Problems the construction of new drags”, Gilem, Ufa, 2003, 68. b) Malinovskii, S. T.; Rechter, M. A.; Stingaci, E. P.; Zavodnik, V. E.; Krimer, M. Z. Crystallography. 1993, 38, 134-138.

[106] Valika, V. V.; Ivanova, R. A.; Chumakov, Yu. M.; Dobrova, B. N.; Stingaci, E. P.; Vlad, L. A.; Macaev, F. Z. Anal. Univers. Stat Mold. Ser. Chim. Biol. 2004, 483-487.

[107] Geronikaki, A.; Babaev, E.; Dearden, J.; Dehaen, W.; Filimonov, D.; Galaeva, I.; Krajneva, V.; Lagunin, A.; Macaev, F.; Molodavkin, G.; Poroikov, V.; Pogrebnoi, S.; Saloutin, V.; Stepanchikova, A.; Stingaci, E.; Voronina, T.; Vlad, L. Bioorg. Med. Chem. 2004, 12, 6559-6568.

[108] Macaev, F.; Rusu, G.; Pogrebnoi, S.; Gudima, A.; Stingaci, E.; Vlad, L.; Shvets, N.; Kandemirli, F.; Dimoglo, A.; Reynolds, R. Bioorg. Med. Chem. 2005, 13, 4842-4850. 